\title{
ANÁLISE DO USO DE KPI'S COM O SUPORTE DE SISTEMAS BI PARA INCREMENTO DA EFICÁCIA DO PROCESSO DECISÓRIO EM UMA ORGANIZAÇÃO JURÍDICA
}

\author{
ANALYSIS OF THE USE OF KPI'S WITH THE SUPPORT OF BI SYSTEMS TO INCREASE THE \\ EFFECTIVENESS OF THE DECISION-MAKING PROCESS IN A LEGAL ORGANIZATION
}

Nilton Cesar Lima

Universidade Federal de Uberlândia, Uberlândia, MG, Brasil, niltoncesar@ufu.br

Waldir Teixeira

Universidade Federal de Uberlândia, Uberlândia, MG, Brasil,waldir.taj@gmail.com

Resumo: O estudo busca compreender se o uso do software Business Intelligence através de relatórios em dashboards, onde evidenciam indicadores em KPI's, são capazes de promover insights estratégicos que aprimorem a eficácia nas decisōes gerenciais da área jurídica. Adotou-se como aporte empírico ao estudo, uma empresa de advocacia localizada na cidade de Uberlândia-MG, considerando-a como estudo de caso único. Trata-se de uma prestadora de serviços jurídicos pesquisada no ano de 2018, que contempla dentre seus instrumentos gerenciais o uso do software através da plataforma Power BI Desktop na versão 2.61 disponibilizado pela Microsoft ${ }^{\oplus}$. A partir de dashboards, buscou-se investigar se o mesmo permite não somente decisóes rápidas como também insights estratégicos para os gestores. Como resultado observado, constatou-se que os gestores da área de advocacia atribuem-se de excelentes indicadores dinâmicos, consistentes e em tempo real, possibilitando-os a melhor tomada de decisão e obtençáo de indicadores que auxiliem na elaboraçáo estratégica da empresa, cooperando, portanto, com a lucratividade da entidade. Tais indicadores observados no software, decorre da base de dados da organizaçáo, que evidencia as principais informaçôes jurídicas em forma de KPI's e configurado em dashboards.

Palavras-chave: Organização jurídica. Business Intelligence. Dashboards. Tomada de Decisão.

Abstract: The study seeks to understand whether the use of Business Intelligence software through reports in dashboards, where they show indicators in KPI's, are capable of promoting strategic insights that improve the effectiveness of management decisions in the legal area. An empirical study, a law firm located in the city of Uberlândia-MG, was adopted as an empirical study, considering it as a single case study. It is a legal services provider researched in the year 2018, which includes among its management tools the use of the software through the Power BI Desktop platform in version 2.61 made available by Microsoft ${ }^{\circ}$. From dashboards, we sought to investigate whether it allows not only quick decisions but also strategic insights for managers. As a result, it was observed that the managers in the area of advocacy are awarded excellent dynamic, consistent and real-time indicators, enabling them to better decision-making and obtain indicators that help in the strategic elaboration of the company, therefore, with the entity's profitability. These indicators, observed in the software, derive from the organization's database, which shows the main legal information in the form of KPI's and configured in dashboards.

Keywords: Legal organization. Business Intelligence. Dashboards. Decision Making. 


\section{Introdução}

Uma empresa, desde sua criação, produz grandes quantidades de dados e informaçôes de vários setores como finanças, marketing, produção, entre outros. Isso ocorre independente do porte, porém, ao longo dos anos, os dados produzidos passaram a ser maiores, assim, companhias tendem a lidar com muitos elementos e, muitas das vezes, não sabem transformá-los em informaçôes úteis que otimizem na tomada de decisão.

Conseguinte, com o surgimento de softwares, o processo decisório passou a ter um suporte mais rico em dados e opçóes a partir do Business Intelligence (BI), que compreende métodos e ferramentas estratégicas que possibilitam ao usuário analisar os resultados e, com base na interpretaçáo dos dados e composição de informaçôes, observou-se que o processo de tomada de decisôes aprimorou o funcionamento das áreas monitoradas. Desse modo, o sistema faz compactaçáo ao gerar grandes quantidades de informaçóes e as transformam em gráficos de maneira integrada, fácil e ágil de serem analisadas (RUD, 2009).

Não obstante, com o auxílio de uma ferramenta BI, é possível, na maioria das vezes, agregar valor à empresa ao tomar decisões melhores usando informações úteis fornecidas por Key Performance Indicators (KPI's), (KLIPFOLIO, 2018). Os KPI’s são quaisquer aspectos mensuráveis que ajude a demonstrar efetividade em alcançar objetivos do negócio (FITZ-GIBBON, 1990). Portanto, escolher os indicadores certos necessita de uma boa compreensão do que é importante para a empresa, já que depende do departamento que mede e acompanha o desempenho evidenciado (REH, 2018).

Além disso, o BI gera dashboards eficientes e rápidos, devido o acesso ao banco de dados em tempo real e tabulação automática (CHUGH e GRANDHI, 2013), o que torna possível orientar o gestor a obter percepçóes denominadas insights, definido pelo dicionário de Cambridge como uma compreensão clara, profunda e às vezes súbitas de um problema ou situação complicada. Vale ressaltar que os dashboards representam painéis gráficos que possibilitam visóes instantâneas e dinâmicas dos indicadores.

O fato é que os KPI's proporcionam relatórios que mesmo diante de perspectivas diversas para suas análises, possam ser otimizados através do BI e oferecer dinamicidade, além de ser em tempo real quanto às informaçóes que confluam decisóes gerenciais. Partindo desse fato, cujo pressuposto é de que a ferramenta BI otimiza a decisão organizacional, este trabalho, portanto, procura responder ao seguinte problema: Como os KPI’s podem servir-se às decisôes gerenciais de modo efetivo através de sistemas BI em uma organização jurídica?

Diante desse contexto e respectiva problematização de pesquisa, buscou-se como objetivo geral do estudo apresentar os principais indicadores em KPI's, a fim de analisar sua contribuição em insights estratégicos promotores da eficiência nas decisóes gerenciais da área jurídica, através de sistema BI.

Ainda como propósitos do estudo lançou-se os seguintes objetivos específicos para análise:

- Indicar um tipo de dashboard que auxilie em bons insights para a tomada de decisão.

- Apontar um software de BI que possa ser utilizado para fazer o uso adequado dos KPI's propostos.

Dessa forma, dentre os diversos setores da economia, fora delimitado abordar uma análise dos KPI's através de sistemas BI como processo decisório em uma organizaçáo prestadora de serviços na área jurídica. O resultado almeja que os gestores possam escolher de modo mais efetivo quais dos indicadores 
adaptados a ferramenta de BI devem ser adotados, para lhes auxiliarem quanto a tomada de decisão que proporcione o alcance de melhores resultados internos, responsáveis por satisfazer o cliente quanto a prestação do serviço jurídico e consequentemente aumentar a lucratividade.

Por fim, o presente estudo se justifica por associar sua relevância ao uso de sistemas de informação, ora aqui adotado como BI, conjuntamente à indicadores configurados em um plano compreendido como KPI's, que se somados possam convergir numa dinamicidade mais efetiva no processo decisório, sobretudo ao se tratar de organização de médio e pequeno porte, cujos gestores são mais propensos às atividades jurídicas que gerenciais. Portanto, obter mecanismos cuja robustez seja captada numa plataforma dinâmica, visual, orientativa e objetiva em informaçóes gerenciais, são meios para que a organização otimize seus resultados em prol da lucratividade esperada.

\section{Fundamentação teórica}

Cabe inicialmente desmistificar o emprego dos termos BI, KPI's, dashboards e insights. Assim sendo, a ordem correta parte pelo BI que se trata do software, a ferramenta que possibilita a compactação de dados e serve de base para que um dashboard projete seus gráficos. Todavia, os dashboards são formados por métricas de indicadores, como por exemplo, os KPI's. Por conseguinte, com a ferramenta de BI, ao exibir um dashboard que evidencie algum indicador, é possível acompanhar resultados e metas que orientam a insights capazes de resultarem em melhores tomadas de decisóes, como pode ser observado na Figura 1, a seguir.

Figura 1 - Explicação dos assuntos abordados

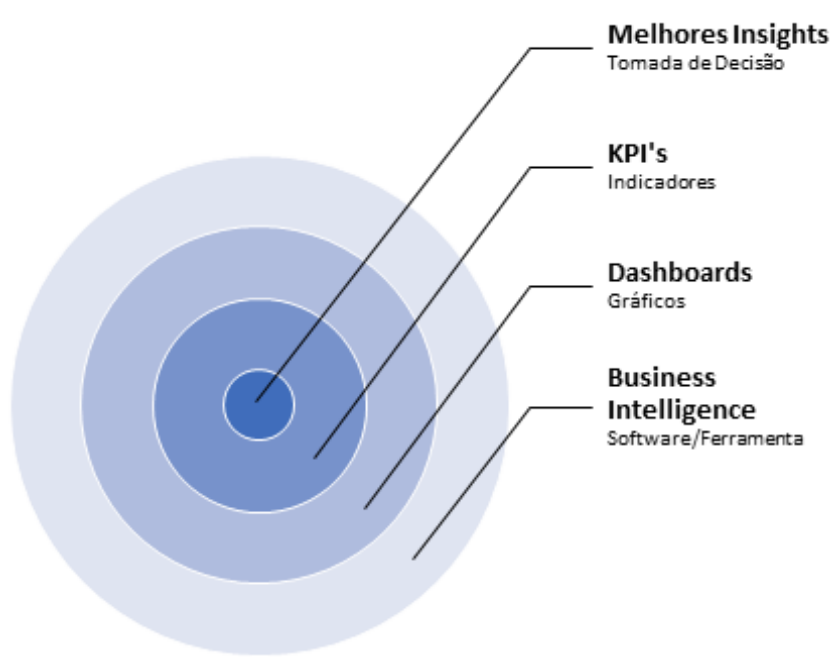

Fonte: Adaptado Gartner (2015).

Observa-se que o núcleo objeto da análise, ora tido como insights s é onde as decisóes serão efetivadas. Formando uma espécie de arquétipo, capaz de filtrar os principais elementos que norteiam uma decisão, caracterizando uma plataforma proporcionada por um software BI que configurada o dashboards e KPI's, capaz de servir de modo dinâmico e remoto o agente decisor. 


\subsection{Sistema BI: funcionalidade}

Entre inúmeros usos, a ferramenta de BI capacita as organizaçôes a obter informaçôes sobre novos mercados, mensurar demanda, adequação de produtos ou serviços para diferentes segmentos e avaliar o impacto dos esforços das áreas operacionais (CHUGH e GRANDHI, 2013). Dessa maneira, o BI se caracteriza por coletar, organizar, analisar, compartilhar e monitorar as informaçôes que oferecem apoio à gestão de negócios (RUD, 2009).

Além disso, o tempo para gerar relatórios à mão é extenso e em alguns casos torna-se inviável, pois consiste em tabular os vários dados brutos obtidos pela contabilidade e outras áreas operacionais da empresa (TREASY, 2018). Conseguinte, os relatórios obtidos manualmente podem ser complexos, estáticos e de difícil entendimento para quem conhece pouco do assunto, o que pode ocasionar perda de oportunidades na leitura dos resultados por gestores.

Ademais, as tecnologias de BI buscam identificar e desenvolver novas oportunidades de negócios estratégicos através da fácil interpretação de grandes volumes de dados (RUD, 2009). Assim, possibilita ao gestor implementar uma estratégia efetiva baseada em intuiçóes percebidas por meio do BI e que podem proporcionar às empresas uma vantagem competitiva no mercado, além de agregar valor ao processo interno.

Dessa forma, a ferramenta de BI contribui para agregar todos os dados não ordenados da empresa e organizá-los de forma que o gestor possa, em tempo real, acessar as informaçóes no momento e local que desejar (GARTNER, 2015). Logo, desde que o software esteja bem estruturado e evidenciando um dashboard que contemple bons KPI's, será possível ao usuário identificar com maior facilidade forças e fraquezas do negócio que possam contribuir para obtenção de bons insights e descobrir novas oportunidades com base nos relatórios mostrados. Sendo assim, resultará em tomadas de decisóes melhores (COKER, 2014).

Outrossim, de acordo com Gartner (2015), os softwares de BI possuem uma interface intuitiva, o que permite que a organização dos dados seja feita de maneira simples para montar painéis de indicadores que atendam os gestores. Assim, a preparaçáo de dados de várias fontes se torna possível rapidamente. Além de fornecer análise avançada com a familiaridade do Excel.

\subsection{Caracterizaçōes decisórias através dos KPI's}

De acordo com Nutini (2015), entende-se como indicadores a "informação quantitativa ou qualitativa que expressa o desempenho de um processo, em termos de eficiência, eficácia ou nível de satisfação que, em geral, permite acompanhar sua evolução ao longo do tempo e compará-lo com outras organizaçóes". Para o autor, o fulcro elementar do uso de indicadores está na sua dimensão de proporcionar decisôes efetivas.

Não obstante, é comum que os gestores possuam dificuldades em analisar todos os dados que a empresa produz, sobretudo selecioná-los e transformá-los em informaçóes úteis que apoiem tomadas de decisôes. Destarte, caberá ao gestor selecionar os KPI's que lhe auxilie em boas tomadas de decisão. 
Para isso, deverá haver previamente um suporte da área de atuação para que se torne possível escolher os melhores indicadores para a organização.

Outro aspecto relevante para o gestor, é a capacidade de discernir sobre o que são dados, informaçôes e indicadores. De acordo com Pavani Jr. e Scucuglia (2011), dados é a menor instância de uma estrutura de indicadores, já informaçôes caracteriza-se como intermediária de uma estrutura de indicadores, e ambos perfazem um indicador que auxilia na tomada de decisóes com maior qualidade do que somente com informações ou dados de modo unilateral.

Tabela 1 - Diferenças entre dados, informaçóes e indicadores

\begin{tabular}{l|l|l}
\hline \multicolumn{1}{c|}{ Dados } & \multicolumn{1}{c}{ Informaçóes } & \multicolumn{1}{c}{ Indicador } \\
\hline $\begin{array}{l}\text { Disponível para manipulação no } \\
\text { banco de dados }\end{array}$ & $\begin{array}{l}\text { Organizadas e já manipuladas em } \\
\text { primeiro nível }\end{array}$ & $\begin{array}{l}\text { Manipulados matematicamente } \\
\text { através de fórmulas }\end{array}$ \\
\hline $\begin{array}{l}\text { Abundantes e armazenados em sua } \\
\text { totalidade }\end{array}$ & $\begin{array}{l}\text { Selecionadas em formatos de telas } \\
\text { e/ou relatórios }\end{array}$ & $\begin{array}{l}\text { Parametrizados em formatos de } \\
\text { gráficos lineares }\end{array}$ \\
\hline $\begin{array}{l}\text { Viabilizados através de coleta de } \\
\text { dados }\end{array}$ & $\begin{array}{l}\text { Viabilizados através de softwares } \\
\text { gerenciais }\end{array}$ & $\begin{array}{l}\text { Viabilizados através de regras de } \\
\text { contagem }\end{array}$ \\
\hline Não tem foco na gestão & Com foco abrangente e dispersivo & $\begin{array}{l}\text { Viabilizados através de regras de } \\
\text { contagem }\end{array}$ \\
\hline
\end{tabular}

Fonte: Pavani Jr. e Scucuglia (2011, p. 218).

Ademais, ater-se de bons indicadores representa mensurar o nível de execução de processos, alcance de objetivos e conduz à melhoria contínua na organização (Nutini, 2015). Ou seja, instrumentaliza-se de açôes decisórias, através dos indicadores, capaz, portanto, de alavancar a lucratividade, bem como ampliar o nível de competitividade organizacional. Não obstante, os KPI’s buscam demonstrar para empresa, através de indicadores, o desempenho dos processos, para que assim haja o entendimento sobre os resultados que vem sendo alcançados, bem otimizar o processo decisório na empresa.

Para Parmenter (2010), os KPI's representam um conjunto de indicadores com foco em abordagens do desempenho organizacional responsáveis para a perenidade da empresa. Não só isso, o autor enumera outras características dos KPI's, sendo algumas delas que indicam claramente qual ação é necessária ser realizada, de maneira que os funcionários compreendam e saibam corrigir as medidas monitoradas. Além de que, articulam responsabilidades para níveis hierárquicos mais baixos. Ainda para o autor, os KPI's permitem uma análise sobre os fatores críticos de sucesso na empresa, sob a perspectiva de dashboards. Por dashboards, o autor ainda argumenta que, são um conjunto de métricas de indicadores relevantes capaz de proporcionar decisóes ao alcance dos objetivos e metas traçadas, sob uma forma visual que facilita a compreensão das informações geradas.

\section{Metodologia}

Para alcançar os objetivos estabelecidos pelo projeto, uma empresa do ramo jurídico com interesse nos resultados fora selecionada para fazer as análises necessárias. Portanto, foi realizado uma pesquisa exploratória responsável pela explicação dos fenômenos, além de descobrir fatos e formular novas ideias e 
hipóteses para um assunto que não existe muitas informações sobre o tema analisado (DUTRA, FLEURY e RUAS, 2008). Além disso, o estudo de caso único auxiliou na criação de constructos e proposiçóes evidenciado de modo empírico (YIN, 2015).

Outrossim, para o estudo de caso, a empresa jurídica selecionada como fonte de informaçóes para o projeto utiliza o Firebird como sistema gerenciador de banco de dados, que utiliza o software Power BI Desktop na versão 2.61, disponibilizado gratuitamente pela Microsoft ${ }^{\circ}$, através de uma conexão ODBC (Microsoft Open Database Connectivity), cuja última consulta, ora obtida como meio para análise foi no dia 30/06/2018.

Tratando-se de um caso único, o protocolo estabelecido contou com os seguintes procedimentos: a coleta e análise dos dados, foi desempenhada através de entrevista semiestruturada com o gestor responsável pela empresa. A entrevista foi conduzida aos moldes da pesquisa-ação, já que um dos autores exerceu participação ativa na empresa durante a atividade da pesquisa. Por conseguinte, o nível de diretividade do pesquisador através de entrevistas semiestruturadas ou abertas, ocorreu a partir dos propósitos e aporte teórico deste estudo, possibilitando o processo ativo de trocas verbais entre o participante e o pesquisador. Ademais, a pesquisa-ação por meio de entrevistas semiestruturadas, não somente possibilitou o momento oportuno em obter dados com a entrevista, conforme os propósitos pretendidos, mas também facilitou, com o exercício funcional do autor na empresa, o procedimento de coleta e análise, já que a atuação se dava diretamente com a ferramenta de software ora apresentada.

A premissa de análise, partiu do pressuposto que o BI é capaz de transformar as informaçôes brutas do banco de dados em exemplos empíricos demonstrados graficamente em modelo de dashboard na discussão dos resultados.

Não obstante, foi utilizado a pesquisa qualitativa que possui caráter subjetivo quanto às particularidades para compreender o porquê da escolha de determinados KPI's considerados adequados para auxiliarem na tomada de decisão de acordo com a necessidade dos gestores dos quais são sócios, cujo exercício profissional de suas ocupaçóes é a advocacia. De modo que, o tão quão os indicadores possam ser claros, ágeis e precisos para que a atividade não se consuma entre o exercício profissional e os desafios da melhor adequação de informaçóes gerenciais, já que se trata de uma empresa de pequeno porte.

Ademais, a pesquisa aplicada contou com efeito prático na região de Uberlândia-MG, e foi útil para encontrar soluções para problemas cotidianos quanto a evidenciação das informaçóes em um ambiente organizacional onde predomina o exercício advocatício, mas que se quer deva desprender-se de atos e decisões gerenciais eficientes decorrentes de indicadores econômico-financeiros.

Portanto, a pesquisa empírica buscou dados relevantes e convenientes obtidos através da experiência do pesquisador quanto ao assunto de BI, e por exercer função na empresa estudada, configurando o método da pesquisa-ação na pesquisa, conjuntamente ao auxílio da entrevista semiestruturada com o gestor jurídico envolvido na utilização do sistema para seus processos de tomada de decisão.

No intuito de apontar os principais indicadores identificando sua aderência às tomadas de decisôes em uma organização jurídica através do BI. Foi necessário criar um critério de identificação dos KPI's. Para tanto, foi levado em conta aspectos como: 
1. Seletividade: escolha de fatores estratégicos relacionados com fatores essenciais ou críticos ao processo decisório para o setor jurídico.

2. Representatividade: ser eficaz quanto a seleção dos dados sobre o processo que é evidenciado.

3. Simplicidade: buscar a fácil compreensão, para que qualquer tipo de usuário possa entender a leitura dos dados demonstrados.

4. Fonte: garantia de que a base de dados está alimentada adequadamente, para que os indicadores permitam a analise os dados com fidedignidade.

Para o tipo de escritório selecionado, foi definido quatro tipos de dashboards capazes de evidenciar indicadores consistentes e relevantes à tomada de decisão. Sendo assim, os dashboards escolhidos foram referentes a visão geral dos dados, os processos ativos, o recorte geográfico, e por fim, a performance do escritório de advocacia quanto aos processos encerrados. Vale ressaltar que para preservaçáo dos dados da empresa, foi ocultado a área do dashboard que detalha o processo referente ao seu número, cliente, reclamante, valor exato referente a causa, provisionamento e encerramento, entre outros. A parte detalhada nada mais é que a fonte de dados brutos obtidas por tabelas semelhantes às do Excel', porém, de forma muito mais simples e poluída, não possibilitando uma clareza e objetividade decisória aos advogados que também se configuram como gestores e decisores na empresa de advocacia.

\section{Discussão dos resultados}

No dashboard, configurado sob uma Visão Geral, conforme demonstrado na Figura 2, em uma situação hipotética: caso o usuário (advogado) precisasse saber de alguma informação dos 81 processos jurídicos que tiveram distribuição nos Fóruns no ano de 2016, bastaria clicar na coluna do ano de 2016, onde lhes seriam apresentados relatórios cujos processos já foram encerrados e quando ocorreu, bem como: a área da causa advogada, o valor sentenciado, valor de provisão e valor de encerramento até a data consultada. Conquanto, para obter tais indicadores manualmente a partir dos dados brutos, demoraria bastante tempo para selecionar e tabular corretamente os dados necessários. 
Figura 2 - Dashboard: Visão Geral

\begin{tabular}{lr}
\hline STATUS & QTD \\
\hline Ativo & 369 \\
Encerrado & 89 \\
\hline Total & $\mathbf{4 5 8}$
\end{tabular}
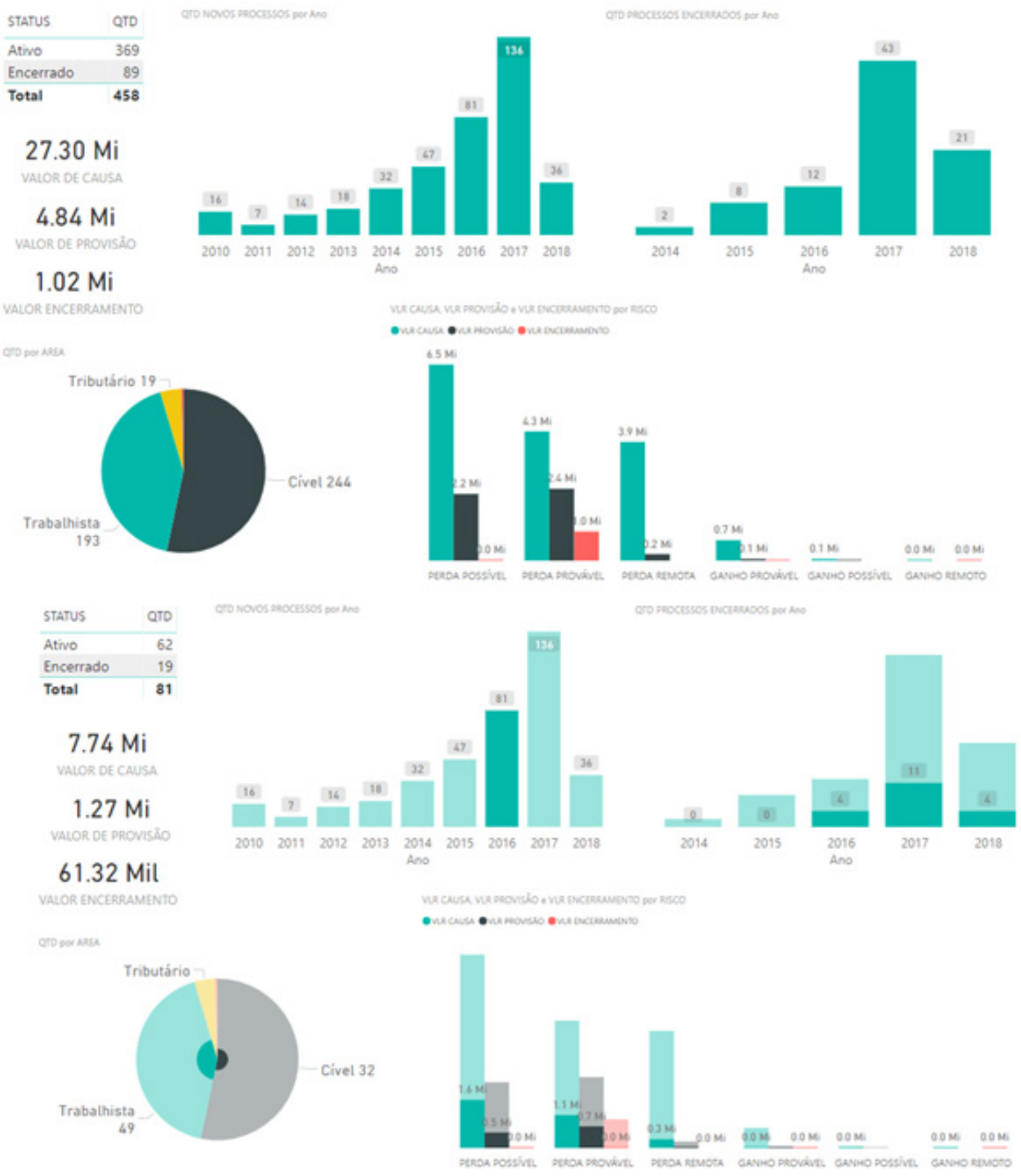

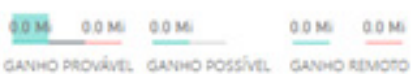

Fonte: Autores.

Em outra hipótese, caso o advogado quisesse puxar apenas os dados referentes aos processos ativos, para que sejam analisados: o ganho ou risco de perda provável da causa, de modo que tal análise também possa ser estendida às melhores decisóes que não impactam com a lucratividade pretendida da empresa. Expresso sob a Figura 3, observou-se, portanto, que: há 53 processos judiciais, dos quais 42 são trabalhistas e 11 cíveis, passíveis de perda provável, permitindo aos advogados, um melhor monitoramento às normas jurídicas, bem como decisôes sob a melhor condução econômico-financeira da advocacia. Além disso, também poderia verificar quando esses processos foram distribuídos e em qual fase eles se encontram. 
Figura 3 - Dashboard Processos Ativos

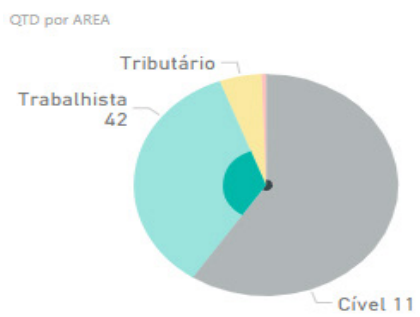

QTD POR TIPO DE RISCO

GANHO PROVÁVEL

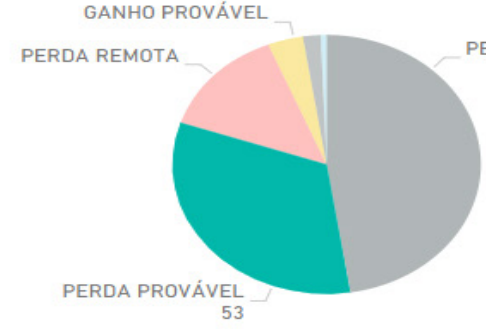

53

QTD PROCESSOS

QTD por FASE

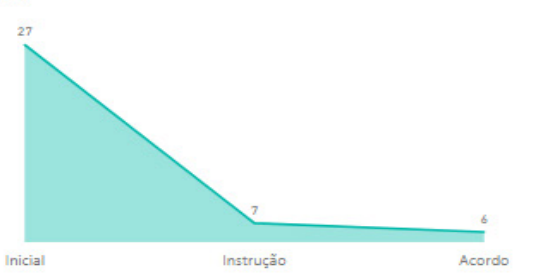

\section{$2.94 \mathrm{Mi} \quad 1.35 \mathrm{Mi}$}

VALOR CAUSA VALOR PROVISÃC

PERDA POSSIVEL VLR CAUSA, VLR PROVISÃO E VLR ENCERRAMENTO por RISCO

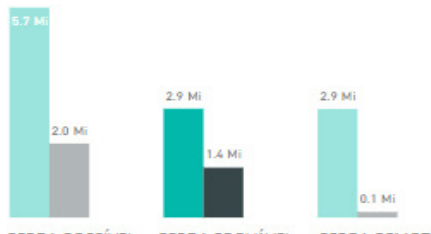

$\underbrace{0.7 \mathrm{Mi}}_{0.1 \mathrm{Mi}} \frac{0.1 \mathrm{Mi} 0.0 \mathrm{Mi}}{0.0 \mathrm{Mi}}$

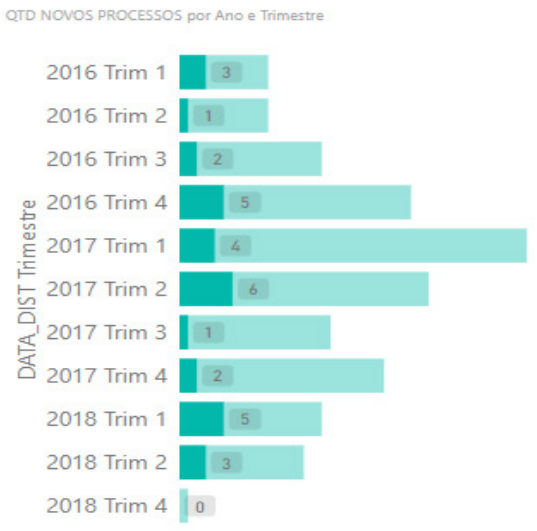

Fonte: Autores.

Para verificar as áreas de atuação e onde está concentrado a maior parte de processos, a empresa de advocacia ainda pode usar o recorte geográfico para suas análises. Possibilitando, contudo, adoçóes decisórias e estratégicas condizentes com a área de atuação e número de processos em cada região estabelecida previamente em suas metas organizacionais.

Figura 4 - Dashboard: Recorte Geográfico

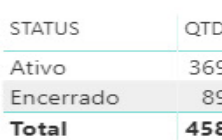

Total

27.30 $\mathrm{Mi}$

VLR CAUSA

4.84 Mi

VLR PROVISÃO

$1.02 \mathrm{Mi}$

VLR ENCERRAMENTO

QTD POr CIDADE E ESTADO
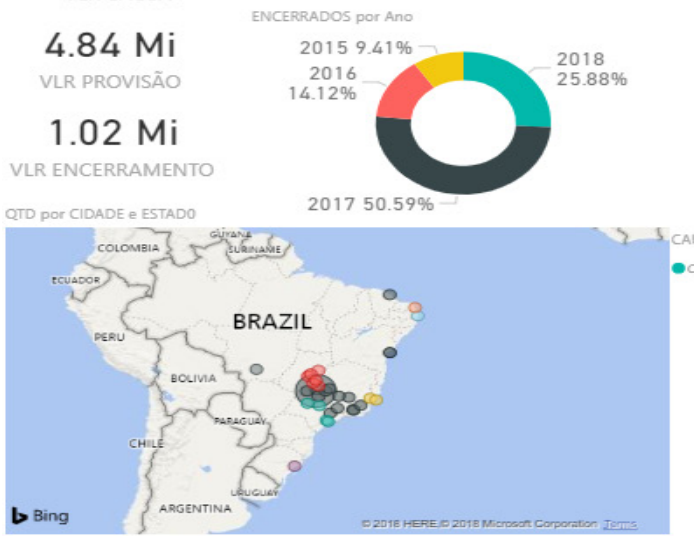

$201750.59 \%$

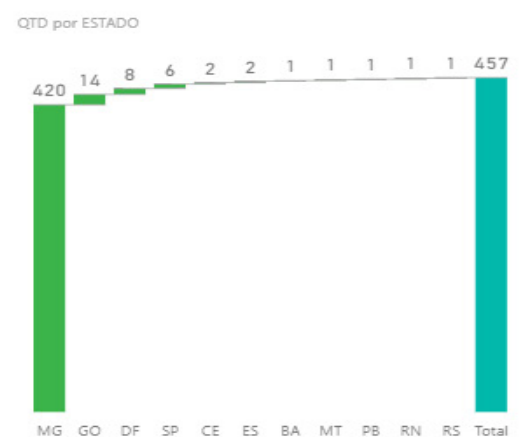

STP por Gipate
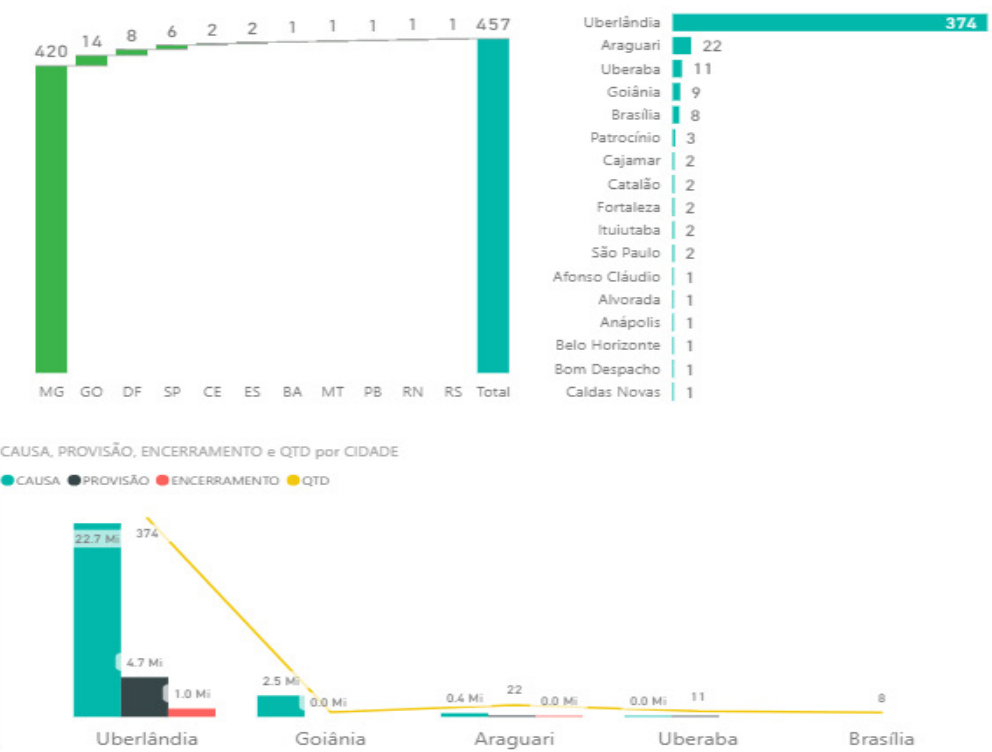

Fonte: Autores.

Observa-se que a Figura 4, permite uma análise mais analítica das áreas/cidades com maiores quantidades de processos como: Uberlândia, Araguari e Uberaba (ambas pertencentes ao Triângulo 
Mineiro). Mas, caso decida analisar pelo risco de valor de causa, terá que analisar melhor as açóes judiciais na cidade de Goiânia-GO, pois mesmo sendo em menor quantidade é evidenciado um risco maior de perda em relaçáo ao valor da causa. Permitindo, acompanhamento prescricional e o monitoramento da causa, como fruto decisório diante da análise.

Entretanto, percebeu-se durante a entrevista que mesmo como a maneira em que os dados são apresentados, não garante instantaneamente ao advogado, ora também compreendido como gestor, que consiga novos e melhores resultados diante do monitoramento e alcance da eficiência pretendida em suas açóes judiciais. De modo que, somente ao longo prazo, e com a familiarização da ferramenta BI, pelos gestores, é que ficará ainda mais fácil a obtenção de insights decisórios. Foi também constatado in loco que apenas o acompanhamento das performances das açóes em um formato confuso de dados e informaçóes em planilhas de Excel", sem o uso do BI, praticamente torna-se impossível a eficiência e dinamicidade decisória pelos gestores.

Ademais, constatou-se também que dentre todos os dashboards, talvez o mais importante para evidenciar o resultado em uma empresa jurídica, é aquele onde poderia ser levado em conta a performance que permita comparar o valor de causa pelo valor de encerramento. Quanto menor o valor de encerramento, caso o escritório tivesse que advogar em defesa, melhor para a empresa de advocacia, pois evidenciaria o seu resultado perante aos processos defendidos. No primeiro quadro, a performance observada mostra que diante de R \$27,3 milhóes em causa, foram pagos até o momento apenas R 1,02 milhóes, o que resulta em $3,7 \%$ da causa. Tal dado, representou um dos principais KPI levantado no estudo, pois a mesma informa de modo analítico o desempenho chave do resultado da defesa de um processo, conforme Figura 5.

Figura 5 - Dashboard: Performance

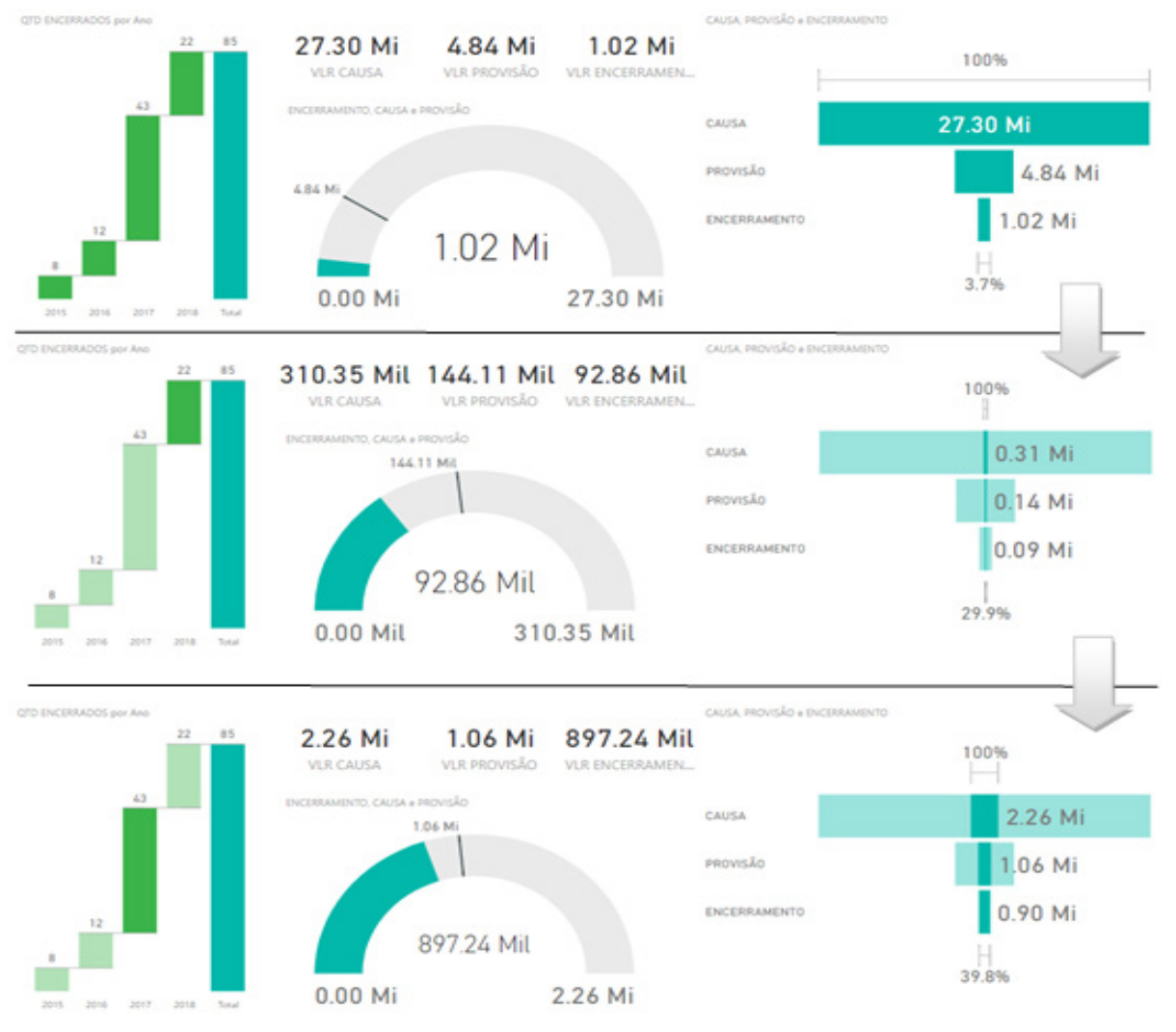

Fonte: Autores. 
Contudo, nessa analítica apresentada na Figura 5, observou-se que caso a performance seja analisada separadamente, é possível notar que no ano de 2018 o valor de causa defendida foi de $\mathrm{R} \$ 310,3$ mil, enquanto o valor do encerramento deu-se em R \$ 92,8 mil, resultando em um KPI de 29.9\%. Nessa avaliação, o gestor precisaria entender que quanto menor o índice de performance, melhor a atuação do escritório, pois significa que do valor total da causa no processo, pela atuação do serviço jurídico, foi possível conseguir encerrá-la em uma porcentagem menor. Na condição de comparação de 2018 com o ano de 2017, a performance foi de $39.8 \%$, de modo que foi possível afirmar que o desempenho de atuaçáo melhorou de 2017 para 2018 até a presente análise.

Por fim, é possível obter um resumo da seleção entre os dashboards e KPI's, apresentados na Tabela 2.

Tabela 2 - Resumo dos Indicadores

\begin{tabular}{|c|c|c|c|c|}
\hline Dashboard & Indicadores & Por quê um KPI? & Base Bruta & $\begin{array}{c}\text { Melhoria Processo } \\
\text { Decisório }\end{array}$ \\
\hline Visão Geral & $\begin{array}{l}\text { A visão geral busca } \\
\text { demonstrar a quantidade } \\
\text { de processos ativos e } \\
\text { encerrados, além do } \\
\text { fluxo de entrada e saída } \\
\text { de processos e de seus } \\
\text { valores quanto a causa, } \\
\text { provisionamento e } \\
\text { encerramento. Não só isso, } \\
\text { detalha também a área do } \\
\text { processo e sua quantidade. }\end{array}$ & $\begin{array}{l}\text { Por ser considerado } \\
\text { o KPI cuja } \\
\text { análise permite a } \\
\text { comparação entre } \\
\text { novas entradas e } \\
\text { saídas de processos. }\end{array}$ & $\begin{array}{l}\text { Status; Número; } \\
\text { Área geográfica; } \\
\text { Causa; Provisão; } \\
\text { Encerramento; Data } \\
\text { da Distribuiçáo e } \\
\text { encerramento dos } \\
\text { processos; }\end{array}$ & $\begin{array}{l}\text { Possibilita visualizar a } \\
\text { quantidade de novos } \\
\text { processos e encerramentos, } \\
\text { além de seus valores } \\
\text { de causa, provisão e } \\
\text { encerramento. Para que } \\
\text { assim, possam validar a } \\
\text { aplicação de estratégias em } \\
\text { outras áreas da empresa e } \\
\text { seu impacto ao painel de } \\
\text { visáo geral. }\end{array}$ \\
\hline $\begin{array}{c}\text { Processos } \\
\text { Ativos }\end{array}$ & $\begin{array}{l}\text { Mostra a quantidade total } \\
\text { de processos ativos na } \\
\text { justiça, seu valor de causa } \\
\text { e provisionamento. Além } \\
\text { da área, tipo de risco e fase } \\
\text { que o mesmo encontra-se. }\end{array}$ & $\begin{array}{l}\text { Permitir ao gestor } \\
\text { lidar com os tipos } \\
\text { de risco: provável, } \\
\text { possível e remoto. } \\
\text { No entanto, por } \\
\text { exemplo, para } \\
\text { lançamentos } \\
\text { contábeis, deverá } \\
\text { levar em conta, } \\
\text { inicialmente, apenas } \\
\text { o provável e com o } \\
\text { dashboard ficará mais } \\
\text { fácil fazer essa seleçáo } \\
\text { e análise. }\end{array}$ & $\begin{array}{l}\text { Status Ativo; } \\
\text { Número; Área; } \\
\text { Causa; Provisão; } \\
\text { Encerramento; Data } \\
\text { Distribuição; Fase; } \\
\text { Risco; }\end{array}$ & $\begin{array}{l}\text { Com a seleção em tempo } \\
\text { real, ficará mais fácil } \\
\text { conferir o passivo do } \\
\text { balanço patrimonial e os } \\
\text { lançamentos jurídicos } \\
\text { envolvidos, o que muitas } \\
\text { das vezes não acontece } \\
\text { devido a demora para } \\
\text { obtençáo dos dados } \\
\text { jurídicos para serem } \\
\text { comparados com o contábil. }\end{array}$ \\
\hline Cidades & $\begin{array}{l}\text { Área de atuação e } \\
\text { localização de onde } \\
\text { há processos ativos e } \\
\text { encerrados e sua respectiva } \\
\text { quantidade. }\end{array}$ & $\begin{array}{l}\text { Devido ao fato } \\
\text { de demonstrar o } \\
\text { recorte de atuaçáo e } \\
\text { as localidades que o } \\
\text { escritório tem como } \\
\text { demanda lidar com } \\
\text { processos. }\end{array}$ & $\begin{array}{l}\text { Status; Número; } \\
\text { Causa; Provisão; } \\
\text { Encerramento; Data } \\
\text { Distribuição; Data } \\
\text { Encerrados; Cidade; } \\
\text { Estado; }\end{array}$ & $\begin{array}{l}\text { Poderá fazer parcerias com } \\
\text { correspondentes/advogados } \\
\text { para atuarem em regióes } \\
\text { mais distantes conforme o } \\
\text { volume de demanda por } \\
\text { cidade. }\end{array}$ \\
\hline
\end{tabular}




\begin{tabular}{|c|c|c|c|c|}
\hline Perfomance & $\begin{array}{l}\text { Indica a qualidade do } \\
\text { serviço prestado pelo } \\
\text { escritório, pois quanto } \\
\text { menor for a taxa de } \\
\text { performance, melhor terá } \\
\text { sido a atuaçáo da área } \\
\text { jurídica se comparada o } \\
\text { valor de causa com o valor } \\
\text { de encerramento. }\end{array}$ & $\begin{array}{l}\text { Por ser considerado } \\
\text { o mais relevante, } \\
\text { uma vez que, } \\
\text { mensura diretamente } \\
\text { a performance e } \\
\text { qualidade do serviço } \\
\text { prestado. }\end{array}$ & $\begin{array}{l}\text { Status Encerrado; } \\
\text { Número; } \\
\text { Causa; Provisão; } \\
\text { Encerramento; Data } \\
\text { Encerrados; }\end{array}$ & $\begin{array}{l}\text { Torna possível comparar } \\
\text { os anos anteriores e buscar } \\
\text { metas para que diminua } \\
\text { na medida do possível } \\
\text { a entrada de processos e } \\
\text { verificar se a diminuição dos } \\
\text { valores encerrados passará } \\
\text { a ser menor ao longo do } \\
\text { tempo. }\end{array}$ \\
\hline
\end{tabular}

Fonte: Autores.

Dessa maneira, é possível compreender que o uso da ferramenta BI, possibilita a aplicação de um controle mais rigoroso na empresa, e auxilia decisóes sobre assumir a condução de novos processos de modo efetivo. Caso necessário, haverá decisão por diminuição da distribuição dos novos processos para que os trabalhos náo se acumulem e impacte no ganho de eficiência das causas defendidas. Já diante dos processos ativos, a partir de sua evidenciação estudada, percebeu-se que o gestor admite que o uso do BI, possibilita atentar-se para auxiliar nas decisóes, minimizando os riscos que se encontrar em cada processo, capaz de reverter melhores ganhos ao escritório de advocacia. Inclusive, possibilitando açóes preventivas para que não haja problemas no caixa do cliente para arcar com o passivo jurídico.

Por último, a performance mede diretamente o resultado que o escritório está alcançando. Assim, se for algo maior que $50 \%$, por exemplo, deverá se preocupar quanto a atuação, condução e eficiência das causas jurídicas, de modo a considerar novos meios para lidar com os processos e se tornar-se melhor no serviço prestado. Ou seja, a eficiência notada ao utilizar-se do BI é o condão de decisões em um serviço jurídico que venha proporcionar vantagens competitivas e lucratividade no longo prazo para o escritório de advocacia.

Face à essas evidenciaçóes constatadas, foi possível observar a relevância da ferramenta BI para o gestor na condução de suas decisôes de modo mais assertivo e célere.

\section{Considerações finais}

É ideal que aconteça a fase experimental dos indicadores em que será testado sua eficiência e, se não se mostrarem adequados ao longo do tempo devem ser alterados ou excluídos. Além disso, é importante que os indicadores sejam periodicamente avaliados a fim de aplicar melhorias contínuas, pois a partir das informaçôes levantadas pode haver novas necessidades de abordar índices que direcione melhores decisões para a organização jurídica.

Outro aspecto conclusivo, é o fato do gestor decisório em uma organização jurídica estar envolvido mais com as normatizaçóes jurídicas, do que propriamente com os atos gerenciais. Ou seja, o advogado na organização estudada, ao mesmo tempo que exerce suas atividades advocatícias, executa também o papel do gestor. Nesse caso, buscando organizar-se por meio de uma plataforma de indicadores, cujo uso do BI exerce plena aderência aos aspectos de competitividade e lucratividade no decurso de suas atividades, devendo para isso ser uma ferramenta fácil de manusear, objetiva e dinâmica. Mesmo se necessário, com uma colaboração inicial de profissionais de outras áreas, que oriente sob modos diversos de atribuir e gerar informaçóes precisas para a organização jurídica. 
Percebeu-se que, na organização pesquisada, a escolha de KPI's, associado ao uso de uma ferramenta BI, tem proporcionado decisóes gerenciais mais eficientes (assertivas e ágeis) aos profissionais da advocacia, de modo a favorecer não somente os resultados pretendidos, como também prover estratégias aos procedimentos e prazos nas atividades jurídicas. Possibilitando inclusive, melhor competitividade e lucratividade nos negócios. Dessa maneira, há melhoria na evidenciação dos dados pertinentes à área jurídica, a partir do emprego do BI, mesmo que os utilitários, compreendidos como gestores e decisores, sejam de outra área (jurídica). Como estudo futuro, tal evidenciação possa ser estendia a demais escritórios de advocacias, cujas principais decisóes econômico-financeira estejam centradas em profissionais da área jurídica.

\section{Referências}

Chugh, R.., \& Grandhi, S. (2013). Why Business Intelligence? Significance of Business Intelligence tools and integrating BI governance with corporate governance. International Journal of E-Entrepreneurship and Innovation, 4 (2), 1-14.

Coker, F. (2014). Pulse: understanding the Vital Signs of Your Business. Ambient Light Publishing, $1^{\text {st }}$ ed., 41-42.

Fitz-Gibbon, C. T. (1990). Performance indicators BERA, Dialogues (2). Bristo, USA: Carol Taylor.

Dutra, J.S., Fleury, M.T.L., \& Ruas, R. (2008). Competências Conceitos, Métodos e Experiências. São Paulo: Editora Atlas S/A, 1, pp. 303.

Gartner, I. G. (2015). Gartner Business Intelligence \& Analytics Summit 2015: CIOs name BI and analytics $1^{\circ}$ investment priority for 2015. Disponível em: <http://gartnerevent.com/NABI13Survey>. Acesso em: 21 março de 2018.

Klipfolio (2018). KPI Examples. Disponível em: <https://www.klipfolio.com/resources/kpi-examples> Acesso em: 11 de maio de 2018.

Nutini, M.A. (2015). Transformando o sistema de indicadores: avaliação do desempenho global sob a ótica do MEG. São Paulo: FNQ.

Parmenter, D. (2010). Key Performance Indicators: developing, implementing and using winning KPIs. New Jersey: John Wiley \& Sons.

Pavani Jr, O., \& Scucuglia, R. (2011). Mapeamento e Gestão por Processos - BPM: gestão orientada à entrega por meio de objetos - metodologia GAUSS. São Paulo: M. Books.

Reh, F.J., (2018). The Basics of Key Perfomance Indicators (KPI). Disponível em: <https://www. thebalance.com/key-performance-indicators-2275156>. Acesso em: 15 de março de 2018.

Rud, O. (2009). Business Intelligence Success Factors: Tools for Aligning Your Business in the Global Economy. Hoboken, N.J: Wiley \& Sons. 
Treasy (2018). Como economizar tempo na elaboração de relatórios gerenciais. Disponível em: <https:// www.treasy.com.br/blog/como-economizar-tempo-na-elaboracao-de-relatorios-gerenciais/> Acesso em: 11 de maio de 2018.

Yin, R.K. (2015). Estudo de Caso: planejamento e métodos. Porto Alegre: Bookman. 